\title{
Knowledge, attitude and health-seeking behavior among family caregivers of mentally ill patients at Assiut University Hospitals: a cross-sectional study
}

\author{
Romany H. Gabra 1* (D, Omnya S. Ebrahim², Doaa M. M. Osman³ and Ghada S. T. Al-Attar ${ }^{4}$
}

\begin{abstract}
Background: Mental illness is associated with misunderstanding and unfavorable attitude worldwide. The belief in its spiritual nature made traditional healers the main service consultants for mentally ill patients. The present study is a cross-sectional study conducted among 425 main family caregivers of mentally ill patients at Assiut University Hospital. The objective of the study was to assess the caregivers' knowledge and attitude towards mental illness as well as their health-seeking behavior for their mentally ill relatives.

Results: The studied caregivers had low scores of knowledge and attitude towards mental illness. Age of the caregivers, their education, and the type of first consulted care and aggressive behavior of the mentally ill relatives were the significant predictors of caregivers' knowledge and attitude towards mental illness. The majority of caregivers (80.2\%) sought advice for the first time from traditional healers. Traditional healers referred only $16.4 \%$ of caregivers' mentally ill relatives to psychiatric care.

Conclusion: The studied caregivers had poor knowledge and a negative attitude towards mental illness. Traditional healers were the main consulted care. So, increasing awareness of mental illness is highly recommended.
\end{abstract}

Keywords: Knowledge, Attitude, Mental illness, Health seeking, Family caregivers, Assiut

\section{Background}

Mental illnesses are defined as "health conditions that are characterized by alterations in thinking, mood, or behavior (or some combination thereof) associated with distress and/or impaired functioning" [1].

Although there is a wide prevalence of mental illnesses (17.6\% worldwide ) [2], they are largely neglected [3] and surrounded by misunderstanding and stigmatizing attitude [4].

Families are the mainstay of caregiving for persons with mental illnesses in the Middle East [5]. Yet, they often lack the knowledge and skills needed to assist their mentally ill relatives [6]. They believed in their Middle Eastern cultures that mental illnesses are attributed to spiritual origin [7].

\footnotetext{
* Correspondence: romany_hosny27@hotmail.com

'Department of Neuropsychiatry, Assiut University Hospital, Assiut University, Assiut, Egypt

Full list of author information is available at the end of the article
}

In Arab countries, mental illness beliefs and practices are broad and complicated issues [8]. Traditional or faith healers are usually consulted for treatment of persons with mental illnesses [9]. This pattern of health-seeking behavior could be predisposed by cultural beliefs regarding the role that demonic control, witchcraft, and the evil eye play in causing symptoms of mental illness [10].

Moreover, the strong family relationships in the Middle East and Arab culture mean that patient admission to a psychiatric hospital produces a stigmatizing label not only for the patient but also for all members of his or her family [11]. In most Middle Eastern countries, there is no interaction between medical professionals and traditional healers [11].

On the other hand, some mentally ill patients tend to somatize their psychological symptoms and usually go to non-psychiatric health care providers before 
they reach the psychiatric clinics or hospitals [12]. This route corresponds with the worldwide allocation to use the medical model for psychiatric illnesses to lessen stigma [13].

In Egypt, The National Survey of Mental Disorders estimated overall prevalence as $16.93 \%$ of the studied adult population. Mood and anxiety disorders were the commonest disorders reported in this study (mood disorders (6.43\%), anxiety disorders (4.75\%), and multiple disorders $(4.72 \%))$ [14].

In the Egyptian community, psychiatric disorders are facing stigmatizing attitude and often met with social rejection [15]. Traditional healers play a key role in primary psychiatric care [16]. The majority of people live in rural areas; however, psychiatric facilities located mainly in major cities. This shortage of mental health facilities enhances the inclination of people towards the use and practice of traditional healing [17].

In Upper Egypt, no previous studies explored knowledge and attitude towards mental illness among family caregivers of mentally ill patients as well as their health-seeking behavior for their relatives. The current study aimed to provide an overview of knowledge, attitude, and pattern of seeking care among family caregivers of mentally ill patients at Assiut University Hospital; Upper Egypt.

\section{Methods}

A cross-sectional study design was carried out among 425 family caregivers of mentally ill patients at Neurological and Psychiatric Hospital at Assiut University Hospitals. The parameters used to estimate the sample size included an estimated proportion of good knowledge among caregivers of 0.5, a 95\% confidence level, and a $5 \%$ margin of error. The sample size was 384 caregivers and after adding $10 \%$ as non-response rate, it was raised up to 425 . The studied caregivers were recruited by a purposive non-probability sampling technique from both outpatient and inpatient psychiatric departments during the period from 11 March 2017 to 14 August 2017.

Caregivers who fulfilled the following criteria were included in the study after obtaining their written informed consent:

For caregivers:

- Aged 21 years old or more,

- Were the main care providers for the patients for $\geq$ 1 year (looking after their daily needs, supervising their medications, taking the patient to the hospital, staying with the patient during the inpatient stay and continuing contact with the hospital staff)
For patients:

- Met the principal diagnosis of any mental disorder according to the Diagnostic and Statistical Manual of Mental Disorders-Fifth Edition (DSM-5) [18] criteria for $\geq 1$ year.

\section{Study instruments}

The enrolled participants were interviewed using a semistructured questionnaire that included four parts:

1. The socio-demographic characteristics of the caregiver and the patient.

2. Modified Attitude towards Mental Illness questionnaire: it is composed of 17 items on threepoints Likert scale (agrees, neutral, and disagree). It measures mental health literacy of the participant regarding causes of mental illness, knowledge of people with mental illness and attitude toward people with mental illness and management of people with mental illness. Higher scores indicate more literacy [19]. The English version of the scale was translated into Arabic by the researchers, and then it was revised by a psychologist and linguistic consultant.

3. The mental condition of the patient; diagnosis of mental illness (was obtained from the patient records), duration of mental illness, regular administration of prescribed medication, frequency of seeking outpatient psychiatric care and times of inpatient psychiatric hospital admission in the past 6 months, and whether previously injured or threatened to injure himself/others, and if previously committed or talked about suicide.

4. The heath-seeking behavior of the studied caregivers for their mentally ill relatives; type of first sought care (whether from psychiatrist or nonpsychiatric physician or traditional healers), those who sought traditional healers were asked about type of traditional healers' management, duration of seeking care from traditional healers, and the reasons for attending psychiatric outpatient clinics after consulting traditional healers [20].

For each participant, the questionnaire filling took $20 \mathrm{~min}$ on average. The researcher assured that the respondents had a comprehensive understanding of the questionnaire with a full explanation of misunderstood questions. About $5 \%$ (20 caregivers) refused to complete the questionnaire and were not included in the studied sample.

\section{Statistical analysis}

The analysis was conducted using SPSS version 20. Mean standard deviation and standard error were used 
to express quantitative data, while qualitative data were presented in frequencies and percentages. Reliability was assessed for modified Attitude towards Mental Illness questionnaire (Cronbach's alpha was 0.68). After performing bivariate analysis, linear regression model was conducted to identify the determinants of poor knowledge and negative attitude (outcome variable). The model included significant variables based on the bivariate analysis as independent variables. A significant $P$ value was considered when it was less than 0.05 .

\section{Results}

As shown in Table 1, the mean age of caregivers was $45.1 \pm 14.3,64 \%$ of the studied sample was equal or above 40 years of age. Females represented $60.7 \%$ of the

Table 1 Characteristics of the studied caregivers at Assiut University Hospitals, 2017

\begin{tabular}{|c|c|c|}
\hline Variable & No. (425) & Percent \\
\hline \multicolumn{3}{|l|}{ Age (years) } \\
\hline$<40$ year & 153 & 36 \\
\hline$\geq 40$ year & 272 & 64 \\
\hline Mean \pm SD & $(45.1 \pm 14.3)$ & \\
\hline \multicolumn{3}{|l|}{ Gender } \\
\hline Male & 167 & 39.3 \\
\hline Female & 258 & 60.7 \\
\hline \multicolumn{3}{|l|}{ Residence } \\
\hline Urban & 59 & 13.9 \\
\hline Rural & 366 & 86.1 \\
\hline \multicolumn{3}{|l|}{ Marital status } \\
\hline Currently married & 295 & 69.4 \\
\hline Unmarried & 130 & 30.6 \\
\hline \multicolumn{3}{|l|}{ Educational status } \\
\hline Illiterate/can read and write & 268 & 63.1 \\
\hline Basic education & 35 & 8.2 \\
\hline Secondary/technical/ & 90 & 21.2 \\
\hline University & 32 & 7.5 \\
\hline \multicolumn{3}{|l|}{ Occupation } \\
\hline Does not work/housewife & 283 & 66.6 \\
\hline Unskilled/skilled worker/farmer & 108 & 25.4 \\
\hline Employee & 25 & 5.9 \\
\hline Professional & 9 & 2.1 \\
\hline \multicolumn{3}{|l|}{ Relationship with the patients } \\
\hline Parents & 208 & 48.9 \\
\hline Brother/sister & 103 & 24.2 \\
\hline Spouse (husband/wife) & 48 & 11.3 \\
\hline Son/daughter & 30 & 7.1 \\
\hline Others* & 36 & 8.5 \\
\hline
\end{tabular}

*Others: (grandmother, uncle/aunt, nephew, cousin) sample compared to $39.3 \%$ males. Most of the studied subjects were rural residents (86.1\%) and about $70 \%$ were married. Two-thirds were not working/housewives and $63.1 \%$ were illiterates/can read and write. Parents represented the main caregivers for about half of the mentally ill patients (48.9\%).

Regarding the characteristics of the studied mentally ill patients, the mean age was $32.7 \pm 12.2$. About half of the patients were females (52.9\%) and singles (48.5\%). Patients who were illiterates/could read and write formed $50.4 \%$, while a small percentage (4\%) completed university education. Only $2.4 \%$ were employed with maintained paid fixed salary even in their illness, while $60 \%$ were unemployed, financially supported by their own families.

Table 2 shows a description of the mental condition of the studied mentally ill patients. The common mental illnesses among the studied patients were bipolar disorder (48\%) and schizophrenia/other related psychotic disorders (42\%). About one-third of patients had aggressive behavior (32.2\%), while patients who previously thought about, threatened, to attempt or attempted suicide were $15.5 \%$. The duration of patients' mental illness

Table 2 Mental condition of the studied mentally ill patients, Assiut University Hospitals 2017

\begin{tabular}{lcl}
\hline Variable & No. $(n=425)$ & Percent \\
\hline $\begin{array}{l}\text { Diagnosis of mental illness } \\
\text { Bipolar disorder }\end{array}$ & 204 & 48.0 \\
$\begin{array}{l}\text { Schizophrenia and other } \\
\text { related psychotic disorders }\end{array}$ & 182 & 42.8 \\
Depression & \\
Child psychiatric disorders & 10 & 6.8 \\
Injuring or threatening to injure anyone & 29.4 \\
Yes & 137 & \\
No & 288 & 32.2 \\
Talking about, threatening, or attempting suicide & 67.8 \\
Yes & 66 & 15.5 \\
No & 359 & 84.5 \\
Duration of current illness in years & & \\
Mean \pm SD (range) & $7.93 \pm 7.32(1-40)$ & \\
Regular administration of prescribed medications & \\
Yes & 415 & 97.6 \\
No & 10 & 2.4
\end{tabular}

Frequency of seeking outpatient psychiatric care in the past 6 months

$$
\text { Mean } \pm \text { SD (range) } \quad 2.17 \pm 1.66(0-10)
$$

Frequency of hospital admission after seeking care in the past 6 months

\begin{tabular}{lll}
0 & 242 & 56.9 \\
1 & 162 & 38.2 \\
2 or more & 21 & 4.9 \\
Mean \pm SD (range) & $0.48 \pm 0.59(0-3)$ & \\
\hline
\end{tabular}


ranged from 1 to 40 years. The mean of frequencies of seeking outpatient psychiatric care in the past 6 months was 2.17 . Nearly $60 \%$ of patients were not admitted to psychiatric hospitals in the past 6 months, compared to $38 \%$ who were admitted only for one time.

As regards the health-seeking behavior, the majority of caregivers (80.2\%) sought advice for the first time from traditional healers for the care of their mentally ill relatives. While only $17.4 \%$ of them sought psychiatric care from the start (Fig. 1).

Table 3 shows that the mean duration of seeking care from traditional healers was 18.77 weeks. The most reported methods of traditional healers' management for mental illness were Holy Koran/Gospel followed by hegab (talisman), and physical methods. The consulted traditional healers referred to small percentage (16.4\%) of mentally ill patients to psychiatric care.

Table 4 shows the results of the modified Attitude towards Mental Illness questionnaire. The mean value of the total scale was $16.90 \pm 4.22$. Regarding the causes of mental illness, $63 \%$ of the study participants disagree that mental illness is genetic, while about $25 \%$ of participants believed that mental illness is caused by spirits. About $77 \%$ of study participants believed that the mentally ill patients (except a few of them) cannot tell the difference between good and bad. About one quarter (24\%) disagreed with the statement of "the mentally ill should not get married" while only $9 \%$ disagreed with the statement of "mentally ill people should be prevented from walking freely in public places".The majority of the studied subjects (82\%) disagreed with the statement of "the mentally ill should live only among themselves". About $60 \%$ disagreed with the statement of "mental illness cannot be cured".

In the multivariable linear regression model (Table 5), the significant predictors of poor knowledge and negative attitude towards mental illness among the studied caregivers were increasing age of the caregivers $(\beta=-0.045)$, not completing any level of education $(\beta=-1.301)$, seeking first care from traditional healer or nonpsychiatrist $(\beta=-2.073)$, and presence of aggressive behavior of the mentally ill relatives $(\beta=-1.434)$.

\section{Discussion}

Poor knowledge about mental illness and negative attitudes toward people with mental illness are widespread [4]. In the present study, the studied caregivers had poor knowledge and negative attitude toward mental illness $(16.90 \pm 4.22)$ compared to Omani relatives of mentally ill patients $(23.66 \pm 4.88)$ [19]. Similarly in Iran, the majority of the families of schizophrenic patients had a negative attitude towards mental illness (88.90\%) [21].

Seeking care from traditional healers for the treatment of mentally ill patients is considered a cultural belief in the Egyptian context [22]. In the current study, about $80 \%$ of the studied caregivers sought care first from traditional healers for their mentally ill relatives. Sixty percent of outpatients attending in Ain Shams University psychiatric clinic, 59\% of schizophrenic patients in Ismailia, and $46.2 \%$ of outpatients in Al Minia University Hospital consulted traditional healers as the first help before coming to psychiatrists [23] [24] [20]. In addition, $40.8 \%$ of bipolar disorder patients recruited from three different governmental and private psychiatric hospitals in Cairo sought traditional healers, of that $62.2 \%$ were before seeking psychiatric services and $37.8 \%$ after [22].

The belief in traditional healing is strongly held in the Arab world and is transmitted through generations. A study in the United Arab Emirates showed that about $60 \%$ of bipolar disorder patients attending the psychiatric clinics at Al Rashid Hospital, Dubai had visited faith healers before seeking medical services [25].

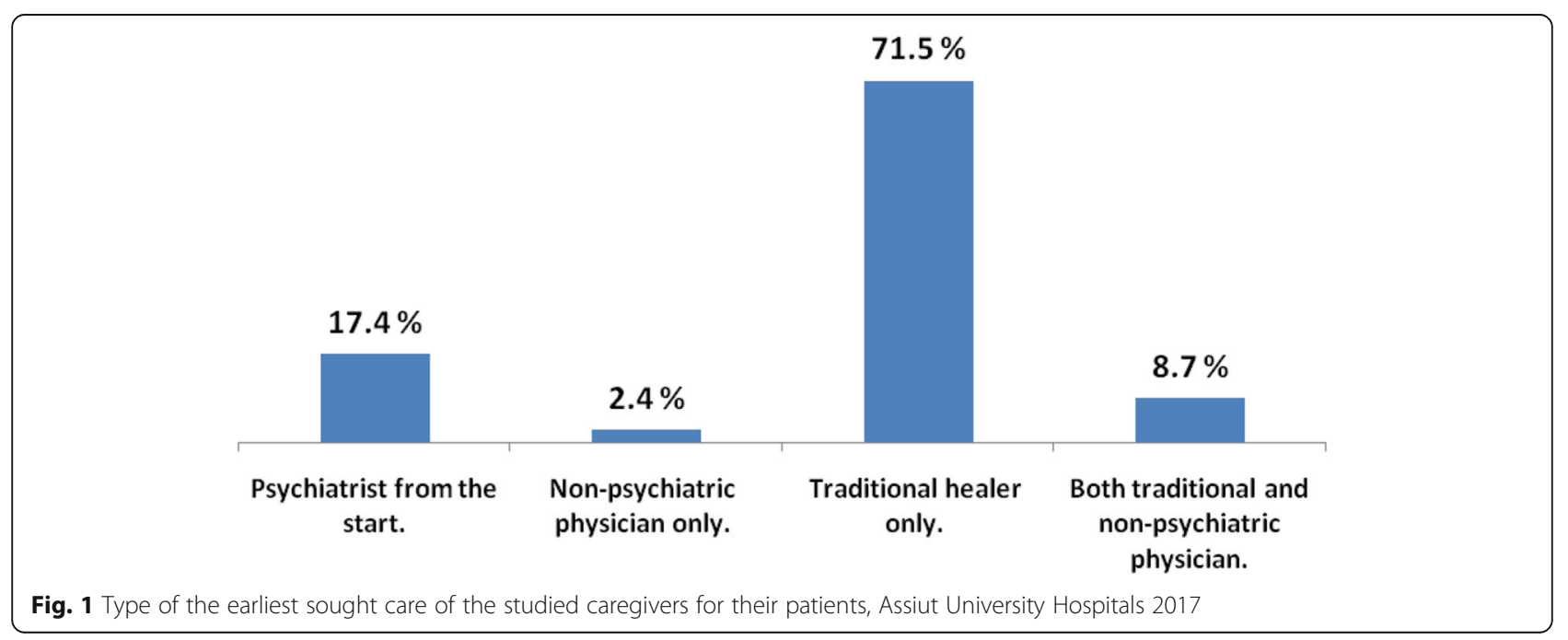


Table 3 Pattern of traditional healers' management for the studied mentally ill patients, Assiut University Hospitals 2017

\begin{tabular}{lcc}
\hline Variable & No. $(n=341)$ & Percent \\
\hline Type of traditional healers management for patient illness (either & 339 & 99.4 \\
traditional healer only or both traditional and non-psychiatric physician) \\
Holy Koran/Gospel & 6 & 1.8 \\
Plants and herb & 101 & 29.6 \\
Hegab (talisman) & 9 & 2.6 \\
Hijama (cupping) & 23 & 6.7 \\
Physical methods (including Zar and beating) & \\
Duration of seeking care from traditional healers (weeks) & $18.77 \pm 0.35(1-480)$ \\
Mean \pm SE (range) & & \\
The reasons for attending psychiatric outpatient clinics after consulting \\
traditional services \\
$\begin{array}{l}\text { Symptom progression } \\
\text { Symptoms did not change }\end{array}$ \\
$\begin{array}{l}\text { Referral by traditional care providers } \\
\text { Symptom recurrence after improvement }\end{array}$ & 69 & 63.0 \\
\hline
\end{tabular}

*Percentages are not mutually exclusive as more than one answer are included

The usage of traditional medicine as a tool for the treatment of psychiatric patients is not limited to Arabic or Middle East countries. It has been reported by other studies that were conducted in Asia (e.g., Singapore) and in Europe (e.g., Norway and Germany) [26] [27] [28].

The result of study conducted in Malay stated that about $44 \%$ of Singaporean mentally ill patients consulted traditional healers as the first contact [26]. While in Norway, $50 \%$ of Sámi and 31\% of Norwegian psychiatric patients used traditional and complementary healing modalities for psychological problems. It was attributed to the greater importance of religion and spirituality and dissatisfaction with the public psychiatric services especially in the Sámi community [27].

A German study at a public hospital showed that half of the psychiatric inpatients had used traditional or complementary medicine parallel to psychiatric treatment and that those patients from a migrant background had predominantly used traditional forms of healing in comparison with the German patients who had used complementary treatment forms [28].

Educational level, socioeconomic standard, the residence of the caregivers in addition to patients' behavior are the factors proved to predict caregivers' literacy and attitude towards mental illness in several studies [29] [30]. As regards to our study, the increasing age of the caregivers significantly predicted poor knowledge and negative attitude towards mental illness $(P=0.036, \beta=-0.045)$. In a systematic review on public attitudes towards mental illness, out of the 33 studies included in the systematic review, 32 reported positive associations between negative attitudes and age [31].
Table 4 Modified Attitude towards Mental Illness questionnaire of the studied caregivers, Assiut University Hospitals 2017

\begin{tabular}{|c|c|c|c|}
\hline Variable & $\begin{array}{l}\text { Agree } \\
N(\%)\end{array}$ & $\begin{array}{l}\text { Neutral } \\
N(\%)\end{array}$ & $\begin{array}{l}\text { Disagree } \\
N(\%)\end{array}$ \\
\hline \multicolumn{4}{|l|}{ Cause of mental illness } \\
\hline Mental illness is genetic & $70(16.5)$ & $87(20.5)$ & $268(63.1)$ \\
\hline Mental illness is caused by spirits & $105(24.7)$ & $32(7.5)$ & $288(67.8)$ \\
\hline \multicolumn{4}{|c|}{ Knowledge of people with mental illness } \\
\hline $\begin{array}{l}\text { One can always tell a } \\
\text { mentally ill person by his } \\
\text { or her physical appearance }\end{array}$ & $386(90.8)$ & $33(7.8)$ & $6(1.4)$ \\
\hline $\begin{array}{l}\text { The mentally ill with a } \\
\text { number of exception } \\
\text { cannot tell the difference } \\
\text { between good and bad }\end{array}$ & $329(77.4)$ & $82(19.3)$ & $14(3.3)$ \\
\hline $\begin{array}{l}\text { Very view in any mentally } \\
\text { ill are capable of true } \\
\text { friendship }\end{array}$ & $338(79.5)$ & $76(17.9)$ & $11(2.6)$ \\
\hline \multicolumn{4}{|c|}{ Attitude towards people with mental illness } \\
\hline $\begin{array}{l}\text { Life has no value for the } \\
\text { mentally ill }\end{array}$ & $155(36.5)$ & $82(19.3)$ & $188(44.2)$ \\
\hline $\begin{array}{l}\text { The mentally ill should } \\
\text { be prevented from having } \\
\text { children }\end{array}$ & $182(42.8)$ & $141(33.2)$ & $102(24)$ \\
\hline $\begin{array}{l}\text { The mentally ill should } \\
\text { not get married }\end{array}$ & $178(41.9)$ & $144(33.9)$ & $103(24.2)$ \\
\hline $\begin{array}{l}\text { Mentally ill people should be } \\
\text { prevented from walking freely } \\
\text { in public places }\end{array}$ & $176(41.4)$ & $210(49.4)$ & $39(9.2)$ \\
\hline $\begin{array}{l}\text { One should avoid all contact } \\
\text { with the mentally ill }\end{array}$ & $25(5.9)$ & $60(14.1)$ & $340(80)$ \\
\hline The mentally ill should not be & $53(12.5)$ & $44(10.4)$ & $328(77.2)$ \\
\hline
\end{tabular}

allowed to make decisions even

those concerning routine events

Care and management of people with mental illness

\begin{tabular}{|c|c|c|c|}
\hline $\begin{array}{l}\text { One should hide his/her mental } \\
\text { illness from his/her family }\end{array}$ & $3(0.7)$ & $9(2.1)$ & $413(97.2)$ \\
\hline $\begin{array}{l}\text { The mentally ill should live only } \\
\text { among themselves }\end{array}$ & $10(2.4)$ & $65(15.3)$ & $350(82.4)$ \\
\hline $\begin{array}{l}\text { Psychiatric hospitals should not } \\
\text { be located in a residential areas }\end{array}$ & $11(2.6)$ & $39(9.2)$ & $375(88.2)$ \\
\hline $\begin{array}{l}\text { There are people who were never } \\
\text { in a mental hospital and are more } \\
\text { disturbed than those who are in a } \\
\text { mental hospital }\end{array}$ & $360(84.7)$ & $42(9.9)$ & $23(5.4)$ \\
\hline Mental illness cannot be cured & $95(22.4)$ & $76(17.9)$ & $254(59.8)$ \\
\hline $\begin{array}{l}\text { Every mentally ill person } \\
\text { should be in an institution } \\
\text { where he/she will be under } \\
\text { supervision and control }\end{array}$ & $322(75.8)$ & $82(19.3)$ & $21(4.9)$ \\
\hline al scale mean \pm SD (range) & & $16.90 \pm$ & $(4-28)$ \\
\hline
\end{tabular}

In the present study, education was a significant predictor of caregivers' knowledge and attitude towards mental illness, where non-educated (illiterates/can read and write) caregivers had poor knowledge and negative 
Table 5 Predictors of knowledge and attitude towards mental illness among the studied participants, Assiut University Hospitals 2017

\begin{tabular}{|c|c|c|c|}
\hline Variable & $\begin{array}{l}\text { Regression } \\
\text { coefficient }\end{array}$ & $P$ value & $95 \% \mathrm{Cl}$ \\
\hline Age of the caregiver & -0.045 & 0.036 & -0.087 to -0.003 \\
\hline Caregiver gender (female) & 0.596 & 0.399 & $-0.791-1.984$ \\
\hline $\begin{array}{l}\text { Caregiver marital status } \\
\text { (single) }\end{array}$ & 0.065 & 0.926 & $-1.311-1.441$ \\
\hline $\begin{array}{l}\text { Caregiver occupation (does } \\
\text { not work/housewife) }\end{array}$ & -0.760 & 0.287 & $-2.162-0.642$ \\
\hline Caregiver residence (rural) & -0.235 & 0.687 & $-1.382-0.911$ \\
\hline $\begin{array}{l}\text { Caregiver education } \\
\text { (illiterate/read and write) }\end{array}$ & -1.301 & 0.009 & -2.274 to -0.327 \\
\hline Caregiver relation (parents) & 0.882 & 0.169 & $-0.376-2.139$ \\
\hline Age of patient & -0.004 & 0.864 & $-0.046-0.039$ \\
\hline Patient gender (female) & 0.025 & 0.951 & $-0.789-0.840$ \\
\hline Injuring (yes) & -1.434 & 0.002 & -2.328 to -0.540 \\
\hline Suicide (yes) & -0.444 & 0.440 & $-1.573-0.684$ \\
\hline $\begin{array}{l}\text { First sought care ( traditional } \\
\text { healer or non-psychiatrist ) }\end{array}$ & -2.073 & $<0.001$ & -3.100 to -1.047 \\
\hline Inpatient admission (yes) & -0.139 & 0.739 & $-0.956-0.679$ \\
\hline Duration of current illness & -0.055 & 0.074 & $-0.116-0.005$ \\
\hline $\begin{array}{l}\text { Diagnosis of mental illness } \\
\text { (schizophrenia and other } \\
\text { related psychotic disorders ) }\end{array}$ & -0.377 & 0.340 & $-1.154-0.400$ \\
\hline
\end{tabular}

attitude towards mental illness $(ß=-1.301, P=0.009)$. Similar findings were reported among the public in Nigeria and Greece. In Nigeria, literate respondents were seven times more likely to exhibit a positive attitude towards the mentally ill as compared to non-literate subjects [32]. Grecian respondents with a high level of education had a favorable attitude towards mental illness and believed that the etiology of mental illness is biological and not God's punishment [33].

Caregivers' residence had no role in their knowledge and attitude towards mental illness in the current study. The residence of the family caregivers had a mixed relationship with their knowledge and attitude towards mental illness in previous studies. Rural residence was associated with poor knowledge and more negative attitude towards mentally ill persons in India, Nigeria, and Ethiopia [34] [35] [36]. This was attributed to a lower level of literacy and more belief in the spiritual origin of mental illness in rural areas [36].

However, Chinese rural residents had more positive attitudes toward people with mental disorders than urban ones. One possible explanation for this evidence is that rural communities may be more tolerant of unusual behaviors, typical of people with mental disorders.
Knowledge and attitude towards mental illness of the studied subjects were not predicted by the diagnosed type of mental illness of their relatives $(P=0.340, \beta=-0.377)$. This is consistent with a study of knowledge, attitude, perception, and belief (KAPB) of mentally ill patients' relatives towards mental illness in India. That study found that KAPB of the relatives was not associated with the patient diagnosed illness $(P<0.05)$ [29]. Controversy with a Sweden study where public negative attitudes and social distance were significantly higher towards psychotic patients than depressed ones [37].

In the present study, aggressive behavior of the mentally ill patient was a predictor of poor knowledge and negative attitude of the studied caregivers towards mental illness $(P=0.002, \beta=-1.434)$. An Indian study compared the literacy and attitude of the family caregivers of mentally ill patients towards mental illness over a 23year period between 1993 and 2016. The study revealed that the area of abnormal behaviors (non-restrained aggressive behavior, weak cognitive control, and bizarre behavior) showed a worsening of negative attitudes [30].

Among the studied caregivers, seeking psychiatric care from the start was a significant predictor of good knowledge and a positive attitude towards mental illness ( $\beta=2.073, P=0.000)$. In concordance with this finding, a meta-analysis of twenty-seven studies among general population revealed that participants with a negative attitude towards mental health help-seeking and stigmatizing attitudes towards people with a mental illness were associated with less active psychiatric help-seeking [38].

\section{Conclusion}

The studied caregivers had poor knowledge and negative attitude towards their mentally ill patients' relatives. The majority of them consulted traditional healers as first help for the care of their mentally ill relatives. The consulted traditional healers referred only a small percentage of patients to psychiatric care. Thus, it is highly recommended to increase public awareness about the nature of mental illness and its management that could promote seeking psychiatric care from the start and decreasing the role of traditional healers.

More focus should be implied on facilitating traditional healers to recognize the severity of mental illness and subsequently refer mentally ill patients to the psychiatrist on time. A further study evaluating the impact of caregivers' knowledge, attitude and pattern of seeking health care on the patient illness outcome should be conducted. Psychiatric institutions should provide educational programs to family caregivers of mentally ill patients to improve their knowledge and attitude towards mental illness and to enable them to cope with the aggressive behavior of their mentally ill relatives and support more control on their relatives' illness. 


\section{Limitations of the study}

The study was conducted at a psychiatric hospital in Upper Egypt and used purposive sampling. This limits the generalizability of the results to all family caregivers of mentally ill patients in the Egyptian community. Moreover, the cross-sectional nature of the study mitigates the inference of the causal relationship between determinants and outcomes.

\section{Abbreviations}

DSM-5: Diagnostic and Statistical Manual of Mental Disorders-Fifth Edition; KAPB: Knowledge, attitude, perception and belief

\section{Acknowledgements}

Not applicable

\section{Ethical approval and consent to participate}

Before starting data collection, approvals to conduct the study were obtained from the Ethical Review Committee of Assiut Faculty of Medicine and the administrative authority in Neurological and Psychiatric Hospital at Assiut University [39]. Prior to the interview, written informed consent was obtained from the literate participants and was signed in the presence of a witness for illiterate ones. Privacy and secrecy of all data were assured by ensuring the anonymity of the questionnaire, interviewing the participant separately in a closed room and keeping data files in a safe place.

\section{Authors' contributions}

$\mathrm{RH}$ contributed in study design, interpretation of the data and preparing and revising the manuscript. OS contributed in study design, collected, analyzed, interpreted the data and prepared the main manuscript. DM contributed in study design, analyzing, interpretation of the data and writing the manuscript. GS contributed in analyzing, interpretation of the data and revising the manuscript. All authors approved the final manuscript.

\section{Funding}

The current study was not supported by any national or international institution or organization

\section{Availability of data and materials}

The data sets generated and/or analyzed during the current study are available from the corresponding author on reasonable request.

\section{Consent for publication}

Not applicable

\section{Competing interests}

The authors declare that they have no competing interests.

\section{Author details}

'Department of Neuropsychiatry, Assiut University Hospital, Assiut University, Assiut, Egypt. ${ }^{2}$ Department of Community, Occupational and Environmental Medicine, Faculty of Medicine, Helwan University, Helwan, Egypt. ${ }^{3}$ Department of Public Health \&Community Medicine, Faculty of Medicine, Assiut University, Assiut, Egypt. ${ }^{4}$ Department of Public Health and Community Medicine, Faculty of Medicine, Assiut University, Assiut, Egypt.

Received: 20 November 2019 Accepted: 2 January 2020

Published online: 17 March 2020

\section{References}

1. CDC. Mental health basics [Internet]. Centers for disease control and prevention. 2013. Available from: https://www.cdc.gov/mentalhealth/basics.htm

2. Steel Z, Marnane C, Iranpour C, Chey T, Jackson JW, Patel V et al (2014) The global prevalence of common mental disorders: a systematic review and meta-analysis 1980-2013. Int J Epidemiol. 43(2):476-493

3. Bebbington P (2001) The World Health Report 2001. Soc Psychiatry Psychiatr Epidemiol. 36(10):473-474

4. El Ahmed NA. Knowledge attitudes and behaviors of psychiatric patients and families in relation to psychiatric patients rights. Alexandria University; 2008.
5. Mahmoud S, Zaki RA (2015) Internalized stigma of mental illness among schizophrenic patients and their families (comparative study). J Educ Pract. 6(12):82-98

6. Shinde M, Desai A, Pawar S. Knowledge, attitudes and practices among caregivers of patients with schizophrenia in Western Maharashtra. 2014;3(5): 516-22.

7. Pridmore SPM (2004) Psychiatry and Islam. Australas Psychiatry. 12(4):380-385

8. Bener A, El-Rufaie OF, Kamran S, Georgievski AB, Faroog A, Rysavy M (2006) Disability, depression and somatization in a low back pain population. APLAR J Rheumatol. 9(3):257-263

9. Salem MO, Saleh B, Yousef SSS (2009) Help-seeking behaviour of patients attending the psychiatric service in a sample of United Arab Emirates population. Int J Soc Psychiatry. 55(2):141-148

10. Sewilam AM, Watson AMM, Kassem AM, Clifton S, McDonald MC, Lipski R et al (2015) Suggested avenues to reduce the stigma of mental illness in the Middle East. Int J Soc Psychiatry. 61(2):111-120

11. Okasha A, Karam E, Okasha T (2012) Mental health services and research in the Arab world. World Psychiatry. 11(February):52-54

12. Okasha A, Karam E (1998) Mental health services and research in the Arab world. Acta Psychiatr Scand. 98(5):406-413

13. Goldberg D (1994) A bio-social model for common mental disorders. Acta Psychiatr Scand Suppl. 385:66-70

14. Ghanem M, Gadallah M, Meky FA, Mourad S, El-Kholy G (2009) National Survey of Prevalence of Mental Disorders in Egypt: preliminary survey. East Mediterr Health J. 15(1):65-75

15. Coker EM (2005) Selfhood and social distance: toward a cultural understanding of psychiatric stigma in Egypt. Soc Sci Med. 61(5):920-930

16. Okasha A. Focus on psychiatry in Egypt. Br J Psychiatry. 2004;185(SEPT.):266-272.

17. Rakhawy MY, Hamdi E (2010). The attitude and use of faith healing by people with mental disorders in Upper Egypt: A Community Survey. Arab J Psychiatry. 21(1):29-49

18. American psychiatric association: diagnostic and statistcal manual of mental disorders, fifth edition, Arlington, VA, American Psychiatric association. 2013.

19. Al-adawi S, Dorvlo AS, SS AL-I (2002) Perception of and attitude towards mental illness in Oman. Int J Scocial Psychiatry. 48(4):305-317

20. Kamal A, Abd Elhameed M, Siddik M (2013) A study on nonpsychiatric management of psychiatric patients in Minia governorate. Egypt. Egypt J Psychiatry. 34(2):128

21. Rahmani F, Ranjbar F, Ebrahimi H, Hosseinzadeh M (2015) The effects of group psychoeducational programme on attitude toward mental illness in families of patients with schizophrenia, 2014. J Caring Sci. 4(3):243-251

22. Assad T, Okasha T, Ramy H, Goueli T, El-Shinnawy H, Nasr M et al (2015) Role of traditional healers in the pathway to care of patients with bipolar disorder in Egypt. Int J Soc Psychiatry. 61(6):583-590

23. Okasha A, Kamel M, Hassan A (1968) Preliminary psychiatric observation in Egypt. Br J Psychiatry. 114(513):949-955

24. El-defrawy MH, Sobhy SA, El-Sheikh E, Tantawy AEA (2000) Non psychiatric traditional and folklore management of schizophrenia reported by patients in Ismailia. Egypt J Psychiatr. 32:215-222

25. Sherra K, Shahda M, Khalil D (2017) The role of culture and faith healers in the treatment of mood disorders in rural versus urban areas in United Arab Emirates. Egypt J Psychiatry. 38(2):79

26. Razali SMMYM (2008) The pathway followed by psychotic patients to a tertiary health center in a developing country: a comparison with patients with epilepsy. Epilepsy Behav. 13(2):343-349

27. Sexton R, Sørlie T (2008) Use of traditional healing among Sámi psychiatric patients in the north of Norway. Int J Circumpolar Health. 67(1):135-146

28. Assion HJ, Zarouchas I, Multamäki S, Zolotova J, Schröder SG (2007) Patients' use of alternative methods parallel to psychiatric therapy: Does the migrational background matter? Acta Psychiatr Scand. 116(3):220-225

29. Das S, Phookun HR (2013) Knowledge, attitude, perception and belief (KABP) of patients relatives towards mental illness; Association with socio demographic characteristics. Delhi Psychiatr J. 16(1):98-107

30. Mehrotra K, Nautiyal S, Raguram A (2018) Mental health literacy in family caregivers: a comparative analysis. Asian J Psychiatr. 31(January):58-62

31. Angermeyer MC, Dietrich S (2006) Public beliefs about and attitudes towards people with mental illness: a review of population studies. Acta Psychiatrica Scandinavica 113:163-179

32. Kabir M, Iliyasu Z, Abubakar IS, Aliyu MH (2004) Perception and beliefs about mental illness among adults in Karfi village, northern Nigeria. BMC Int Health Hum Rights. 4:1-5 
33. Madianos MG, Economou M, Hatjiandreou M, Papageorgiou A, Rogakou E (1999) Changes in public attitudes towards mental illness in the Athens area (1979/1980-1994). Acta Psychiatr Scand. 99(1):73-78

34. Srinivasan TN, Thara R (2001) Beliefs about causation of schizophrenia: Do Indian families believe in supernatural causes? Soc Psychiatry Psychiatr Epidemiol. 36(3):134-140

35. Gureje OYE, Lasebikan VO, Ephraim-Oluwanuga O, Olley BO, Kola L (2005) Community study of knowledge of and attitude to mental illness in Nigeria. Br J psychiatr try. 186:436-441

36. Shibre T, Negash A, Kullgren G, Kebede D, Alem A, Fekadu A et al (2001) Perception of stigma among family members of individuals with schizophrenia and major affective disorders in rural Ethiopia. Soc Psychiatry Psychiatr Epidemiol. 36(6):299-303

37. Svensson $B$, Hansson $L$ (2016) How mental health literacy and experience of mental illness relate to stigmatizing attitudes and social distance towards people with depression or psychosis: a cross-sectional study. Nord J Psychiatry. 70(4):309-313

38. Schnyder N, Panczak R, Groth N, Schultze-Lutter F (2017) Association between mental health-related stigma and active help-seeking: systematic review and meta-analysis. Br J Psychiatry. 210(4):261-268

39. The official site of Assiut university [Internet]. 2019. Available from: www. aun.edu.eg

\section{Publisher's Note}

Springer Nature remains neutral with regard to jurisdictional claims in published maps and institutional affiliations.

\section{Submit your manuscript to a SpringerOpen ${ }^{\circ}$ journal and benefit from:}

- Convenient online submission

- Rigorous peer review

- Open access: articles freely available online

High visibility within the field

- Retaining the copyright to your article 